\title{
Design and Testing of a Natural Convection Solar Tunnel Dryer for Mango
}

\author{
Isaac Nyambe Simate and Sam Cherotich \\ Department of Agricultural Engineering, University of Zambia, P.O. Box 32379, Lusaka, Zambia \\ Correspondence should be addressed to Sam Cherotich; samchero@gmail.com
}

Received 5 June 2017; Revised 7 August 2017; Accepted 11 September 2017; Published 16 October 2017

Academic Editor: Koray Ulgen

Copyright (c) 2017 Isaac Nyambe Simate and Sam Cherotich. This is an open access article distributed under the Creative Commons Attribution License, which permits unrestricted use, distribution, and reproduction in any medium, provided the original work is properly cited.

\begin{abstract}
A natural convection solar tunnel dryer comprising three major units, a solar collector unit, a drying unit, and a vertical bare flat-plate chimney, was constructed. No-load tests with a horizontal configuration of air entry into the collector resulted in a bidirectional air flow in the dryer. To correct this undesirable situation, an air guide at the collector was incorporated to ensure that air entered in a vertical direction. To investigate its performance, drying experiments with mango were carried out at the University of Zambia, Department of Agricultural Engineering. Uncertainties in the parameters measured in the experiment were analysed and quantified. The results showed that, under solar radiation between 568.4 and $999.5 \mathrm{~W} / \mathrm{m}^{2}$, air temperature of up to $65.8^{\circ} \mathrm{C}$ was attained at the collector unit. The average relative humidity values were $30.8 \%, 6.4 \%$, and $8.4 \%$ for the ambient, collector, and drying unit, respectively. Under these conditions, mango with an initial moisture content of $85.5 \%$ (wet basis) was dried to $13.0 \%$ (wet basis) in 9.5 hours. The collector, drying, and pick-up efficiencies were found to be $24.7 \%, 12.8 \%$, and $35.0 \%$, respectively. The average temperature difference between the chimney air and ambient air was $12.1^{\circ} \mathrm{C}$, and this was sufficient in driving the flow of air through the dryer.
\end{abstract}

\section{Introduction}

Due to their perishable nature, fruits such as mangoes are likely to suffer from high postharvest losses if they are not utilized immediately after maturity. In Zambia, the postharvest losses of fruits are estimated to be $50 \%$ of their annual production [1]. Some of the reasons for the high losses are poor harvesting technologies, lack of or underdeveloped handling and processing technologies, and failure of the market to consume most of the supply during the harvest season.

One of the effective methods in reducing postharvest losses in fruits is solar drying technology. According to Kumar et al. [2], solar drying has the capacity to meet the growing demand for healthy but low cost natural foods in addition to providing income in a sustainable way. However, solar dryers require careful design and experimentation to determine the drying time, solar radiation, and attainable air conditions such as temperatures, relative humidity, and air speed for optimum drying in order to obtain a high quality product.

There are two broad categories of solar dryers, that is, natural (passive) and forced (active) convection solar dryers. Natural convection solar drying systems rely on solar energy for their operation $[3,4]$. The air heated by the sun becomes less dense than the ambient air resulting in a difference in air densities which in turn creates a buoyancy force. The buoyancy force or wind pressure or both cause air to be driven in and out of the dryer [5]. Forced convection systems, however, require a fan driven by grid electricity or generator to move air through the dryer. Alternatively, harnessing solar energy through a solar PV module employing a solar powered fan [6-8] could be a much viable option for active solar drying systems in areas without access to grid electricity. The major advantage of forced convection systems is their high efficiency in air movement, making them suitable for drying large amounts of material and high moisture content products like grains, papaya, cabbage, kiwi and others $[5,9]$. 


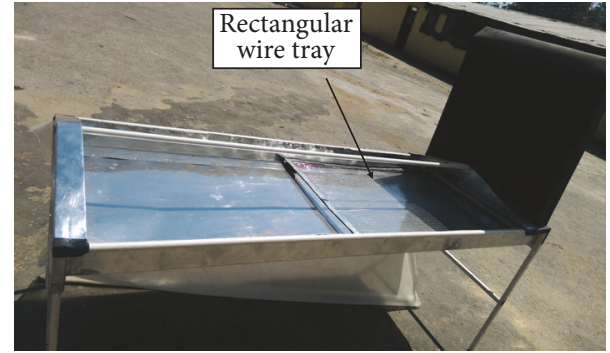

FIGURE 1: Solar tunnel dryer showing the rectangular tray.

Although forced convection systems have higher efficiency than natural systems, their application in rural areas presents some challenges. The requirements for a fan and a source of power to drive the fan make forced convection solar dryers more complex and relatively more expensive than natural convection solar dryers [3]. In most rural areas in developing countries such as Zambia, access to grid electricity is still lacking while areas with access to electricity are prone to load shading. Limitation in the viability of a grid powered fan in an active solar drying system is hence apparent. Further, using a solar PV module to power a fan in an active solar dryer has some downsides which include high initial cost and high chances of theft of the PV module if the system is to be operated in a field setup remote from close monitoring.

In the current study, we investigate the performance of a locally made natural convection solar tunnel dryer under natural weather conditions of Lusaka, Zambia, using mango as the product. The natural convection solar tunnel fruit dryer (Figure 1) used in this study was fabricated from locally available materials by Cherotich [10] having been adapted from forced convection solar tunnel dryers [6-8]. The dryer was used to develop an appropriate thin layer drying model for mango [11]. There is no other literature on natural convection solar tunnel drying of mango under Zambian weather conditions. In this study, the design and testing of the natural convection solar tunnel dryer with the necessary adjustments to achieve satisfactory performance are presented. Previous studies on the design of natural convection solar tunnel dryers include that done by Berinyuy et al. [12] who adapted the dryer from Esper and Mühlbauer [13] but added a $12 \mathrm{~cm}$ diameter and $3.8 \mathrm{~m}$ high, black-painted PVC chimney instead of a solar PV module and a fan, to drive the air through the dryer. Berinyuy et al. [12] then carried out experiments drying indigenous vegetables of Cameroon. In the current study, the dryer was made in modular form; that is, the chimney and legs could be detached from the collector-drying chamber subassembly for ease of transportation and assembly.

\section{Materials and Methods}

2.1. Determination of the Dryer Dimensions. This study adopted the general design of solar tunnel dryers from past studies [6-8] but with the incorporation of a solar chimney to make the dryer a natural convection type. Solar dryers are constructed to dry a recommended amount of product
TABLE 1: Sizes of the different components in the solar tunnel dryer.

\begin{tabular}{lccccc}
\hline & Dryer part & $\begin{array}{c}\text { Length, } \\
\mathrm{m}\end{array}$ & Width, $\mathrm{m}$ & $\begin{array}{c}\text { Height, } \\
\mathrm{m}\end{array}$ & $\begin{array}{c}\text { Surface } \\
\text { area, } \mathrm{m}^{2}\end{array}$ \\
\hline$(1)$ & Drying unit & 1.00 & 0.75 & - & 0.75 \\
$(2)$ & Drying tray & $0.96^{*}$ & $0.72^{*}$ & - & $0.69^{*}$ \\
$(3)$ & Collector unit & 1.00 & 0.75 & - & 0.75 \\
$(4)$ & Chimney unit & & 0.75 & 0.75 & 0.56 \\
$(5)$ & Dryer legs & 0.02 & 0.02 & 0.60 & - \\
\hline
\end{tabular}

${ }^{*}$ Effective tray dimensions and area.

known as the loading density (LD). It is a measure of the amount of product loaded per unit tray area and the LD aids in sizing the drying area of the dryer. The LD is calculated mathematically according to [9]

$$
\mathrm{LD}=\frac{W_{\text {FreshProduct }}}{A_{\mathrm{d}}}
$$

where $W_{\text {FreshProduct }}$ is the weight of fresh product, $\mathrm{kg}$, and $A_{\mathrm{d}}$ is the area of the tray in the drying chamber in $\mathrm{m}^{2}$.

For mango, an $\mathrm{LD}$ of $2.6 \mathrm{~kg} / \mathrm{m}^{2}$ previously used by Akoy et al. [14] was used. A unique feature of solar tunnel dryers is that the collector unit and the drying unit have the same size in terms of area. Therefore, by sizing the drying unit, the collector unit size is set automatically and this emphasizes the simplicity in construction of solar tunnel dryers. However, for experimental purposes and minimization of cost, a drying unit size slightly less than $1 \mathrm{~m}^{2}$ was chosen as shown in Table 1 .

Since the chimney unit is usually attached at one end of the drying unit, its width was defined by the width of the drying unit. To simplify the design and to keep the dryer as compact as possible for transportation purposes, the chimney height was made equal to its width. A summary of the major components and their dimensions is shown in Table 1.

2.2. Description of the Dryer and Its Components. The fabricated solar tunnel dryer shown in Figure 1 consists of three major components: the collector unit, the drying unit, and a bare flat-plate chimney unit. The solar collector unit was a flat-plate type with air flow above the absorber plate while the cover was a transparent $200 \mu \mathrm{m}$ polythene sheet. The reason for using this type of collector unit is because of its low thermal losses $[15,16]$. The absorber plate was made from a flat Galvanized Iron (GI) sheet and in order to increase the solar absorptivity of the plate, it was painted matte black. To minimize heat losses to the surrounding, the base and sides of the collector unit were insulated with $20 \mathrm{~mm}$ Styrofoam sheets.

The drying unit and the collector unit were made in one subassembly and from the same materials and configured in series. The base and sides of the drying unit were also clad with $20 \mathrm{~mm}$ Styrofoam sheets to minimize heat losses to the ambient air. To provide for the drying of the product, the drying unit was mounted with a removable wire mesh tray to hold the product during the drying as shown in Figure 1.

The chimney was a bare flat-plate type collector constructed from a $0.3 \mathrm{~mm}$ thick flat GI sheet with a channel 


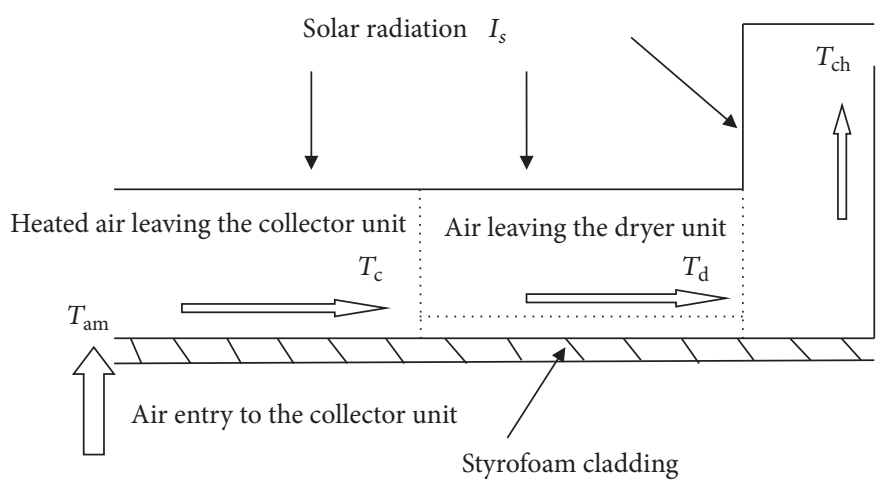

FIgURE 2: Air flow in the solar tunnel dryer.

depth of $0.1 \mathrm{~m}$ and served the purpose of reheating the air exiting the drying unit. The solar radiation receiving surface of the chimney was painted matte black to absorb as much of the incident solar radiation as possible.

The whole dryer assembly was supported by four legs $0.6 \mathrm{~m}$ above the ground, and the collector-drying unit subassembly, the chimney, and the legs were all detachable to allow for easier transportation.

2.3. Mode of Operation of the Dryer. The mode of operation of the dryer given in Figure 2 assumed a unidirectional air flow. The solar radiation falling through the transparent cover in both the collector and drying units heats the air entering the collector unit through convective heat transfer at the cover and the absorber plate.

The heated air becomes less dense compared to ambient air and, as a result, buoyancy pressure is generated which causes the air in the collector unit to be displaced to the drying unit.

At the drying unit, if the product is loaded, mass and heat transfer between the product and the air takes place and hence the air temperature is expected to reduce while the relative humidity increases due to moisture transfer from the product to the air. The heat and mass transfer processes which take place at the same time cause the product to dry with time. In addition to drying caused by the heated air, the solar radiation through the transparent cover of the drying unit facilitates the product to be dried directly. Therefore in the solar tunnel dryer, the product is dried through convective heat transfer and direct radiation and these result in high drying rates.

With no product loaded in the drying unit, the air from the collector unit continues to be heated as it passes through the drying unit and therefore becomes hotter than the air at the collector unit. Through the chimney unit, the air exiting the drying unit is further heated and rises by natural convection to the outside and the cycle repeats itself as long as there is solar radiation.

2.4. Experimentation. The experiments were carried out during the months of October and November at the Department of Agricultural Engineering at the University of Zambia,
Lusaka, with the following coordinates: latitude $15.3^{\circ} \mathrm{S}$; longitude $28.3^{\circ} \mathrm{E}$.

2.4.1. No-Load Experiments. During the no-load experiments, the dryer was operated from 09:00 hours to 16:00 hours a day without any product loaded for drying. The parameters of interest were attainable air temperatures in the dryer, relative humidity reduction, and air flow direction under solar radiation typical of the study area.

Thermocouple type temperature probes (Campbell Scientific Inc., model: 108 -L accuracy $\pm 0.01^{\circ} \mathrm{C}$ ) capable of measuring temperatures ranging between -5 and $+95^{\circ} \mathrm{C}$ were used to measure air temperatures at the following points: entry to the collector unit $\left(T_{\mathrm{am}}\right)$, exit of the collector unit $\left(T_{c}\right)$, exit of the drying unit $\left(T_{d}\right)$, and the exit of the chimney unit $\left(T_{\text {ch }}\right)$. Relative humidity probes (Campbell Scientific Inc., model: HMP35D; accuracy at $+20^{\circ} \mathrm{C}$ is $\pm 2 \% \mathrm{RH}(0-90 \% \mathrm{RH})$ and $\pm 3 \% \mathrm{RH}(90-100 \% \mathrm{RH}))$ that were capable of measuring humidity ranges of 0 and $100 \%$ were used to measure air relative humidity at the following points: the entry point to the collector $\left(\mathrm{RH}_{\mathrm{am}}\right)$, collector unit exit $\left(\mathrm{RH}_{\mathrm{c}}\right)$, and the drying unit exit $\left(\mathrm{RH}_{\mathrm{d}}\right)$. A pyranometer (Kipp \& Zonen Delft BV, model: CM11, irradiance range: $0-1,400 \mathrm{~W} / \mathrm{m}^{2}$, sensitivity: between 4 and $6 \mu \mathrm{V} / \mathrm{Wm}^{-2}$ ) placed on a flat horizontal ground surface near the solar tunnel dryer was used to measure solar radiation. All the probes were connected to a multiprobe data logger (Campbell Scientific Inc., model: CR 1000) which recorded the air temperatures, relative humidity, and solar radiation every minute. The air flow in the dryer was measured at 30-minute intervals with a digital air flow meter (Keonders Instruments BV, The Netherlands, model: $\mu \mathrm{P} 2308$, measurement range: $0-30 \mathrm{~m} / \mathrm{s}$, accuracy: $<20 \mathrm{~m} / \mathrm{s}= \pm 2 \%$, $\geq 20 \mathrm{~m} / \mathrm{s}= \pm 5 \%$ ) by inserting its probe through the plastic cover of the dryer. These recorded air conditions varied with time of the day and defined the drying of the product.

2.4.2. Mango Drying Experiments. These experiments involved running the dryer with the tray loaded with mango slices. The instrumentation used in the no-load experiments (Section 2.4.1) was all used in the same way but there was an addition of a balance for monitoring the weight loss of the samples. 


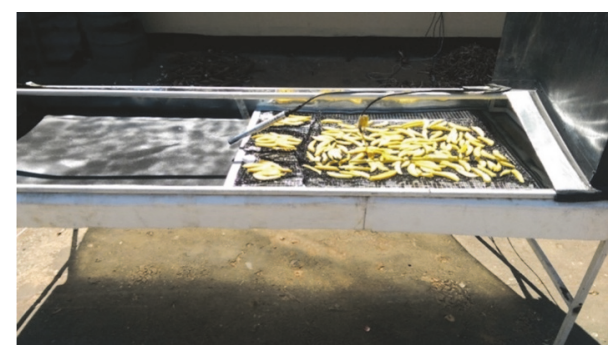

FIGURE 3: Solar tunnel dryer loaded with the sliced mango.

The procedure described below was followed:

(i) Ripe mango was purchased from the local market on an evening before the day of the experiment and kept under room temperature overnight.

(ii) Starting at $07: 00 \mathrm{~h}$ on the day of the experiment, mango was cleaned, peeled, and sliced into approximately $5 \mathrm{~mm}$ thickness [17].

(iii) To determine the initial moisture content, three 10 g samples were removed from the sliced mango and their moisture content was determined using the standard method of moisture content determination as described by AOAC [18].

The moisture content on wet basis, $\mathrm{MC}_{\mathrm{wb}}$, was calculated according to

$$
\mathrm{MC}_{\mathrm{wb}}=\frac{W_{\mathrm{w}}}{W_{\mathrm{w}}+W_{\mathrm{dm}}} * 100 \%,
$$

where $\mathrm{MC}_{\mathrm{wb}}$ is the moisture content, percent wet basis; $W_{\mathrm{w}}$ is the weight of water, g; and $W_{\mathrm{dm}}$ is the weight of dry matter, $g$.

The moisture content on dry basis $\mathrm{MC}_{\mathrm{db}}$ was calculated according to

$$
\mathrm{MC}_{\mathrm{db}}=\frac{\mathrm{MC}_{\mathrm{wb}}}{100-\mathrm{MC}_{\mathrm{wb}}},
$$

where $M C_{d b}$ is the moisture content, dry basis.

(iv) For the drying experiment, samples of mango (weighing about $60 \mathrm{~g}$ each) placed on small polyethylene nets were positioned at three locations on the drying tray as shown in Figure 3 to monitor the weight loss. The rest of the drying tray area which was covered by a similar net was spread with a thin layer of sliced mango. At full capacity, the drying unit could carry $1.8 \mathrm{~kg}$ of sliced mango, hence a LD of $2.6 \mathrm{~kg} / \mathrm{m}^{2}$.

(v) By 09:00 h, the setup of the equipment and preparation of the product were complete and the drying of the product started. The samples were weighed at 30minute intervals on an electronic top balance (Mettler Instruments BV, Switzerland, model PE 3000, maximum weighing capacity: $3,100 \mathrm{~g}$, sensitivity: $0.1 \mathrm{~g}$ ). Through the data logger, air temperatures, $T_{\mathrm{c}}, T_{\mathrm{d}}, T_{\mathrm{ch}}$, and $T_{\mathrm{am}}$; relative humidities $\mathrm{RH}_{\mathrm{c}}, \mathrm{RH}_{\mathrm{d}}$, and $\mathrm{RH}_{\mathrm{am}}$; and finally, the solar radiation were recorded as the drying progressed until the end of the experimental day (16:00 h).

(vi) The weight loss measurements were done by unloading the small nets containing the three samples and weighing on the digital balance. This took approximately 60 seconds each time it was done.

(vii) From the weight loss measurements, the moisture content of the sample at any time was calculated using

$$
\mathrm{MC}_{\mathrm{dbt}}=\left(\frac{W_{\mathrm{st}}-W_{\mathrm{dm}}}{W_{\mathrm{dm}}}\right),
$$

where $\mathrm{MC}_{\mathrm{dbt}}$ is the moisture content (dry basis) at any time; $W_{\text {st }}$ is the weight of the sample at any time, g; and $W_{\mathrm{dm}}$ is the weight of the dry matter of the sample, $\mathrm{g}$.

(viii) At the end of a drying day, if the mango was still losing weight, it was packed tightly in polyethylene bags and stored under room temperature to prevent any moisture migration in and out of the product during the night.

(ix) The following day, the mango was unpacked from the polythene bags and reloaded into the dryer to continue drying until there was no significant change in the weight of the samples in successive weight measurements.

2.5. Dryer Performance Evaluation. The collector unit, the drying unit, and the chimney unit were analysed for their performance as detailed in the following sections.

2.5.1. The Collector Unit Efficiency. The collector efficiency expresses the heat gained as a ratio of the solar radiation falling on its surface. The solar collector unit efficiency was calculated using [19]

$$
\eta_{\mathrm{c}}=\frac{\dot{m} C_{p}\left(T_{\mathrm{c}}-T_{\mathrm{am}}\right)}{I_{s}},
$$

where $\eta_{c}$ is the collector efficiency; $\dot{m}$ is the air mass flow rate per unit collector area, $\mathrm{kg} / \mathrm{m}^{2} \mathrm{~s} ; C_{p}$ is the specific heat capacity of the air, $\mathrm{J} / \mathrm{kg} \mathrm{K} ; T_{\mathrm{c}}$ is the temperature of air leaving the collector, $\mathrm{K} ; T_{\mathrm{am}}$ is the temperature of air entering the collector, $\mathrm{K}$; and $I_{s}$ is the solar radiation, $\mathrm{W} / \mathrm{m}^{2}$.

2.5.2. The Drying Efficiency and Pick-Up Efficiency. In the drying unit, two parameters were evaluated, that is, the drying efficiency and the pick-up efficiency. For natural convection solar dryers, the drying efficiency is given by [20]

$$
\eta_{\text {drying }}=\frac{W h_{f g}}{I_{\mathrm{ST}} A_{\mathrm{ec}}},
$$

where $\eta_{\text {drying }}$ is the drying efficiency; $W$ is the total moisture removed, $\mathrm{kg} ; h_{f g}$ is the latent heat of vaporization of water at the dryer air temperature, $\mathrm{J} / \mathrm{kg}$; $I_{\mathrm{ST}}$ is the total solar radiation 
TABLE 2: Uncertainties in the parameters measured in the experiments.

\begin{tabular}{|c|c|c|c|c|c|c|c|}
\hline Parameter measured & Units & $\mathrm{UX}_{\text {bias }}$ & $\mathrm{UX}_{\text {random }}$ & $\mathrm{UX}_{\text {resolution }}$ & $\mathrm{UX}_{\text {operator }}$ & $\mathrm{UX}_{\text {environment }}$ & $\mathrm{UX}_{\text {overall }}$ \\
\hline Air remperature & ${ }^{\circ} \mathrm{C}$ & \pm 0.134 & \pm 0 & \pm 0 & \pm 0 & \pm 0 & \pm 0.134 \\
\hline Air relative humidity & $\%$ & \pm 0.89 & \pm 0 & \pm 0 & \pm 0 & \pm 0.04 & \pm 0.89 \\
\hline Solar radiation & $\mathrm{W} / \mathrm{m}^{2}$ & \pm 4.46 & \pm 0 & \pm 0 & \pm 0 & \pm 2 & \pm 4.89 \\
\hline Mass of sample & $\mathrm{g}$ & \pm 0.04 & \pm 0 & \pm 0.06 & \pm 0.036 & \pm 0 & \pm 0.08 \\
\hline Airflow & $\mathrm{m} / \mathrm{s}$ & \pm 0.004 & \pm 0 & \pm 0.006 & \pm 0.003 & \pm 0 & \pm 0.008 \\
\hline
\end{tabular}

received during the drying period, $\mathrm{J} / \mathrm{m}^{2}$; and $A_{\mathrm{ec}}$ is the effective area for solar collection, $\mathrm{m}^{2}$. For a dryer that receives only direct radiation on the product, $A_{\mathrm{ec}}$ can be taken as the area of the drying tray.

However, for a solar tunnel dryer, the drying product receives both direct radiation from the sun and hot air from the collector. The drying efficiency therefore has to consider these two sources of energy used in the evaporation of moisture from the product. For this reason, (5) was combined with (6) to give (7) which takes into consideration the two sources of energy.

$$
\eta_{\text {drying }}=\frac{W h_{f g}}{I_{\mathrm{ST}}\left[A_{\mathrm{d}}+\eta_{\mathrm{c}} A_{\mathrm{c}}\right]},
$$

where $A_{\mathrm{c}}$ is the collector area, $\mathrm{m}^{2}$, and $A_{\mathrm{d}}$ is the drying tray area, $\mathrm{m}^{2}$.

The pick-up efficiency is a parameter that defines the utilized capacity of the heated air in evaporating the moisture from the product. The pick-up efficiency was calculated according to [15]

$$
\eta_{\text {pick-up }}=\frac{h_{\mathrm{d}}-h_{\mathrm{c}}}{h_{\mathrm{as}}-h_{\mathrm{c}}},
$$

where $\eta_{\text {pick-up }}$ is the pick-up efficiency; $h_{\mathrm{d}}$ is the absolute humidity of the air leaving the drying unit, $\mathrm{kg} / \mathrm{kg} ; h_{\mathrm{c}}$ is the absolute humidity of the air leaving the collector unit and entering the drying unit, $\mathrm{kg} / \mathrm{kg}$; and $h_{\mathrm{as}}$ is the adiabatic saturation humidity of the air entering the drying unit, $\mathrm{kg} / \mathrm{kg}$.
2.6. Uncertainties and Errors in Measured Parameters. Parameters that were measured in these experiments include air temperature, air relative humidity, solar radiation, sample weight, and air flow in the dryer. Errors and uncertainties could have arisen from the design of the experiments, inaccurate reading of instruments, calibration, and instrument resolution. According to Moffat [21], an estimate of the possible residual error in a measurement after all proposed corrections have been made is the uncertainty attributed to that measurement and is that the overall uncertainty of a measurement is the root-sum-square combination of the uncertainties of all the subordinate measurements considered to be part of the present measurement.

Uncertainty due to repeatability or random error is determined from the standard deviation of the sample data, while uncertainty due to systematic errors is estimated heuristically from containment limits, containment probability, and the inverse error distribution. Therefore the uncertainty due to systematic error for a normally distributed error is given by (9) and for uniformly distributed error is given by (10) [22]:

$$
\mathrm{UX}=\frac{L}{\phi^{-1}((1+p) / 2)},
$$

where $\pm L$ are the containment limits which may be taken from manufacturer tolerance limits, calibration records or certificates, or statistical process control limits; $p$ is the containment probability; and $\phi^{-1}()$ is the inverse normal distribution function.

$$
\mathrm{UX}=\frac{L}{\sqrt{3}} .
$$

The overall uncertainty is therefore given by [22]

$$
\mathrm{UX}_{\text {overall }}=\sqrt{\left\{\mathrm{UX}_{\text {bias }}^{2}+\mathrm{UX}_{\text {random }}^{2}+\mathrm{UX}_{\text {resolution }}^{2}+\mathrm{UX}_{\mathrm{operator}}^{2}+\mathrm{UX}_{\text {environment }}^{2}\right\}},
$$

where $\mathrm{UX}_{\text {overall }}$ is the overall uncertainty; $\mathrm{UX}_{\text {bias }}$ is the uncertainty due to reference attribute bias and persists during a measurement session; $\mathrm{UX}_{\text {random }}$ is the uncertainty due to repeat measurement and manifests itself as differences in measured value from measurement to measurement during a measurement session; $\mathrm{UX}_{\text {resolution }}$ is uncertainty due to the smallest discernible value indicated in a measurement; $\mathrm{UX}_{\text {operator }}$ is uncertainty due to errors introduced by the person taking the measurement and producing a systematic bias towards a measurement; and $\mathrm{UX}_{\text {environment }}$ is due to errors introduced by changing environmental conditions such as temperature and humidity.

\section{Results and Discussions}

3.1. Uncertainty Analyses. The overall uncertainties of the measured parameters are presented in Table 2. All the uncertainties were calculated according to methods described 
by NASA [22]. For all the parameters measured, the error contributing to measurement bias uncertainty was considered to be normally distributed with $97.5 \%$ containment probability. For the temperature measurement, this was the only contributor to the overall uncertainty.

The error contributing to repeatability, that is, random uncertainty, was not observed for all the measured parameters. This is because the parameter values change continuously with time as the sun, which the main contributor to the weather, changes its position throughout the day.

The error contributing to resolution of measuring instruments was not considered for the air temperature, air relative humidity, and solar radiation. The instruments that measured temperature, relative humidity, and solar radiation were connected to the data logger which recorded the measurements automatically. However, for the mass and air flow measurements, the operator read the measurements and recorded them. The error contributing to resolution was considered to be uniformly distributed and therefore the uncertainty was calculated using (10) with $100 \%$ containment probability.

The operator uncertainty error source was considered to be normally distributed with containment limits assumed to be half of the resolution error and $90 \%$ containment probability. For the air temperature and relative humidity and solar radiation, this error was considered zero as the measuring instruments for these parameters were not handled during the experiment after the initial setup. For the moisture and air flow, measurements were done every 30 minutes and the operator influence was present.

The main factors that could have contributed to environmental uncertainty are temperature, wind, and solar radiation. For the air temperature, the changes in temperature were related to the changes in the reading of the temperature instrument. The probes were shielded with aluminium foil to avoid direct radiation as recommended by the manufacturer. The mass balance was operated in a room at ambient temperature, with no direct radiation and very low wind flow. The air flow meter was operated for a few seconds every 30 minutes to take a reading and the environmental factors were assumed to have no influence during the measurement periods.

3.2. No-Load Results. A total of five no-load experiments were conducted and from these experiments, the first three were carried out with the air entry point located at the collector unit having no air guide as shown in Figure 4. From this configuration, the air entry into the collector unit was directly in a horizontal manner.

The average air velocities in the ambient, $V_{\mathrm{am}}$, and in the collector, $V_{\mathrm{c}}$, were $0.36 \mathrm{~m} \mathrm{~s}^{-1}$ and $0.04 \mathrm{~m} \mathrm{~s}^{-1}$, respectively. With these relatively low air velocities, an undesirable air flow which can be described as bidirectional according to this study was experienced. This bidirectional air flow was evidenced from the recorded air temperatures at the collector entry, collector exit, drying unit exit, and chimney exit abbreviated previously as $T_{\mathrm{am}}, T_{\mathrm{c}}, T_{\mathrm{d}}$, and $T_{\mathrm{ch}}$, respectively. These air temperatures are plotted in Figure 5.

On the other hand, the desired air flow pattern which can be described as unidirectional referring to air entry from

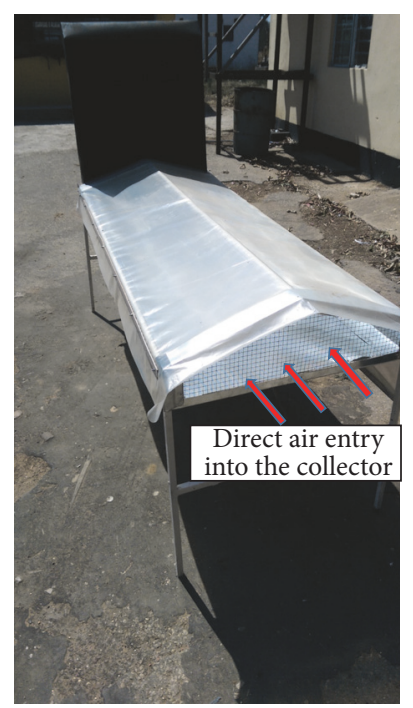

FIGURE 4: Solar tunnel dryer without an air guide.

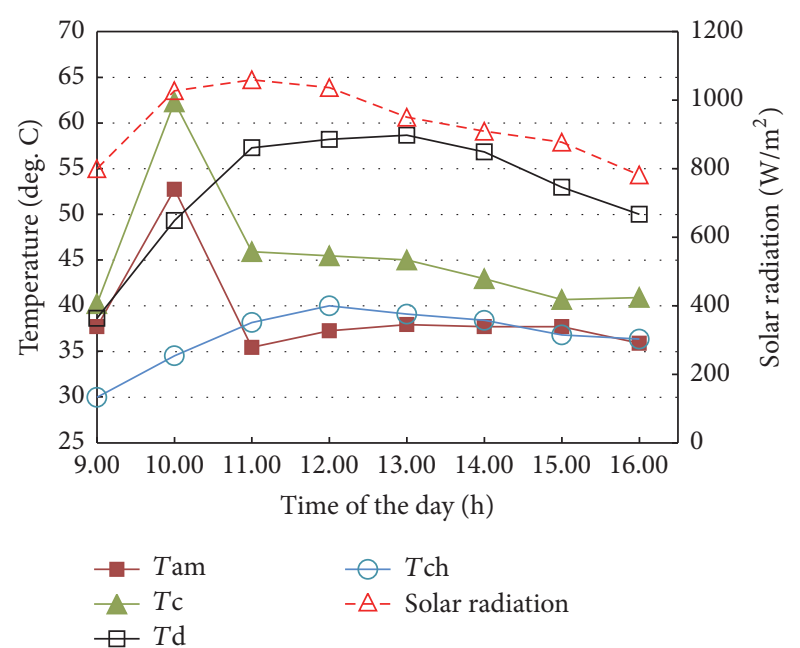

FIgURE 5: Temperatures and solar radiation with no air guide at entry.

the collector unit and exit through the chimney unit would show the air getting progressively hotter. However this was not the case (as seen in Figure 5) and this was attributed to an undesirable air exit from the collector entry point.

From Figure 5, the observed pattern of the air temperatures shows a complete distortion in the air flow. Between 09:00 $\mathrm{h}$ and 10:00 $\mathrm{h}$, the air temperature $T_{\mathrm{c}}$ was higher than the air temperatures in all the other measured points and this was contrary to the results that would be expected for a unidirectional air flow under no-load conditions. In a unidirectional air flow, air is heated progressively from the collector unit, then at the drying unit, and finally at the chimney unit and, therefore, $T_{\mathrm{c}}$ should be less than $T_{\mathrm{d}}$ and $T_{\mathrm{d}}$ should be less than $T_{\text {ch }}$. Between 10:00 h and 11:00 h, a sharp drop in the air temperatures $T_{\mathrm{am}}$ and $T_{\mathrm{c}}$ is observed amidst increasing solar radiation while the air temperatures $T_{\mathrm{d}}$ and $T_{\mathrm{ch}}$ continued to rise. This suggested two relationships in the 


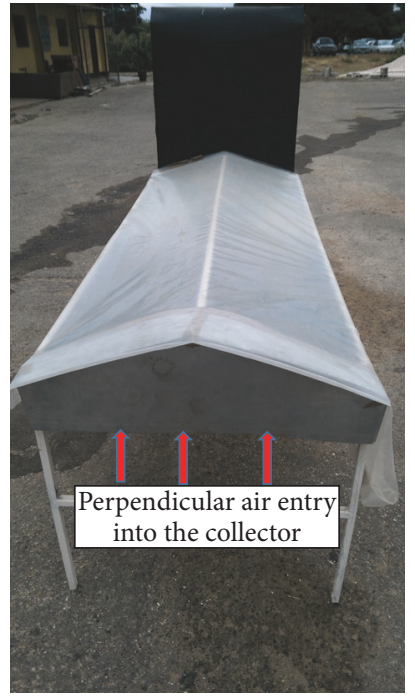

FIGURE 6: Solar tunnel dryer with an incorporated air guide.

air temperatures which were relationship between $T_{\mathrm{am}}$ and $T_{\mathrm{c}}$ and relationship between $T_{\mathrm{d}}$ and $T_{\mathrm{ch}}$ under the registered average solar radiation of $930.0 \mathrm{~W} / \mathrm{m}^{2}$.

This data suggests that there was some hot air mixing with cold air at the entry and exit points, the result of which was that the recorded mean ambient air temperature of $39.1^{\circ} \mathrm{C}$ at the collector entry point was greater than the recorded chimney exit temperature of $36.8^{\circ} \mathrm{C}$. With these conditions, it was deduced that the buoyancy pressure was negative or, in other words, the air flow in the chimney was in the reverse direction [16]. This was attributed to the configuration of the air entry point which was directly adjacent to the collector unit and allowed air to enter in a horizontal manner and thus could be influenced by external wind flow. With the possible cause of the anomalous bidirectional air flow identified, an air guide at the entry unit was incorporated in order to block air entering directly in a horizontal direction but allowing it in a vertical direction (see Figure 6); and the last two no-load experiments were conducted using this configuration.

With the air guide in place, the air flow in to the collector unit was confined to a perpendicular entry relative to the horizontal axis of the collector unit as shown in Figure 6. The results of the air temperatures with the air guide in place showed a unidirectional air flow as shown in Figure 7. The average values for $T_{\mathrm{am}}, T_{\mathrm{c}}, T_{\mathrm{d}}$, and $T_{\mathrm{ch}}$ were obtained as $32.8^{\circ} \mathrm{C}, 49.5^{\circ} \mathrm{C}, 52.6^{\circ} \mathrm{C}$, and $40.5^{\circ} \mathrm{C}$, respectively, and these were expected as the pattern described a flow from the collector entry point and exit at the chimney unit.

After the drying unit, a temperature drop of $12.1^{\circ} \mathrm{C}$ from the drying unit temperature was observed at the bare flatplate chimney exit. This drop in air temperature at the chimney exit was unexpected because the chimney unit, a bare flat-plate solar collector, was expected to continue heating the air from the drying unit to a higher temperature than the drying unit air temperature; that is, $T_{\text {ch }}$ should be greater than $T_{\mathrm{d}}$. This phenomenon of drop in temperature at the chimney unit could be explained by the high

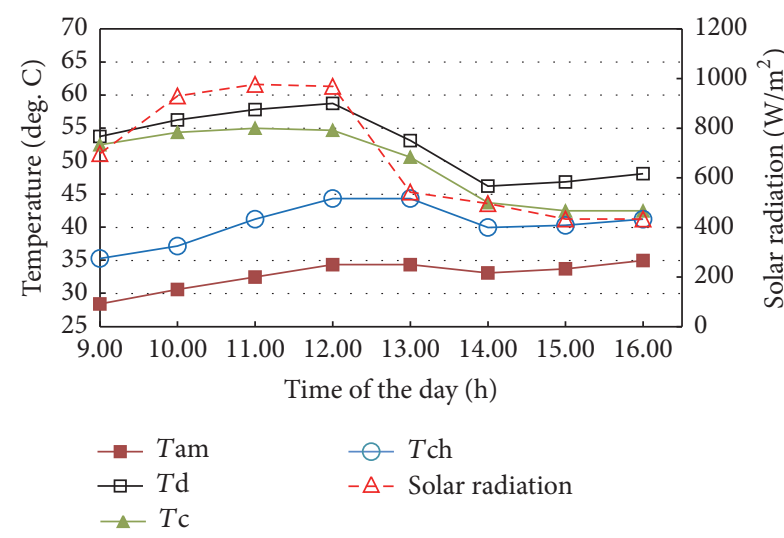

FIGURE 7: Air temperatures with air guide in place.

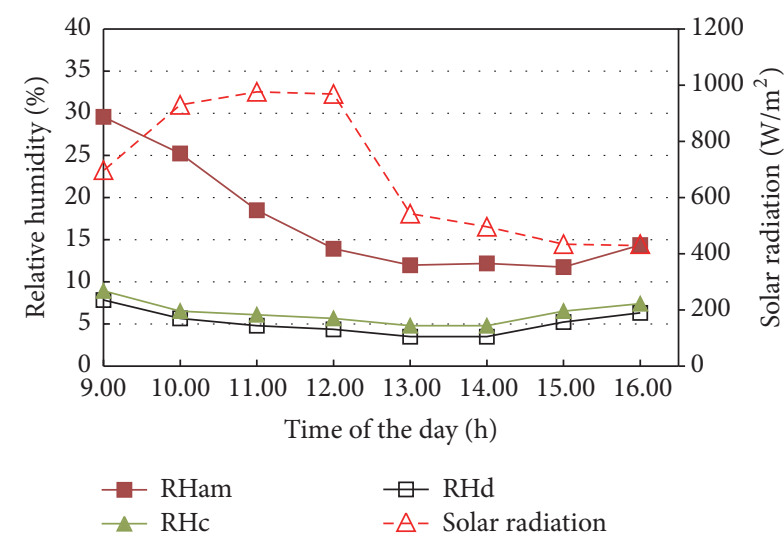

FIGURE 8: No-load relative humidity and solar radiation with the air guide in place.

thermal heat losses associated with bare flat-plate collectors [16].

The relative humidity associated with the air temperatures in Figure 7 is shown in Figure 8. It is noticed that the relative humidity of air at collector entry $\left(\mathrm{RH}_{\mathrm{am}}\right)$ decreased appreciably from $29.6 \%$ at $09: 00 \mathrm{~h}$ to values as low as $12.0 \%$ at 13:00 $\mathrm{h}$ while the solar radiation increased sharply to a peak value of $968.8 \mathrm{~W} / \mathrm{m}^{2}$ in this time period. After 12:00 h a sharp decline in the solar radiation to a value of $434.0 \mathrm{~W} / \mathrm{m}^{2}$ at 16:00 $\mathrm{h}$ was experienced and this was due to a cloud cover that was observed during this period. Within the recorded solar radiation, the air relative humidity was reduced to average values of $6.3 \%$ and $5.1 \%$ in the collector $\left(\mathrm{RH}_{\mathrm{c}}\right)$ and dryer $\left(\mathrm{RH}_{\mathrm{d}}\right)$, respectively.

At this point, it is worth noting that the sharp increase in the solar radiation produced a corresponding decrease in the relative humidity thus pointing out a dependence of the relative humidity on the solar radiation. Despite the low air velocities of $0.36 \mathrm{~ms}^{-1}$ and $0.04 \mathrm{~ms}^{-1}$ for $V_{\mathrm{am}}$ and $V_{c}$, respectively, the pattern of air temperatures and relative humidity shown in Figures 7 and 8, respectively, indicated that a unidirectional air flow was achieved with the air guide in place. The air velocity of $0.04 \mathrm{~ms}^{-1}$ translates into a volume air flow of $10.3 \mathrm{~m}^{3} / \mathrm{h}$ which compares well to the air flow 


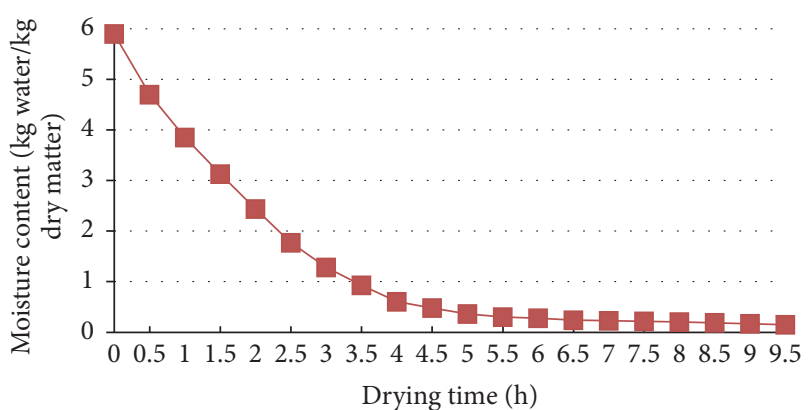

Figure 9: Mango drying curve.

of $9.68 \mathrm{~m}^{3} / \mathrm{h}$ obtained by Berinyuy et al. [12] in a natural convection solar tunnel dryer.

With a unidirectional flow achieved and the observed good conditioning (low relative humidity) of the ambient air by the dryer (Figure 8), 4 sets of mango solar drying experiments were done with the dryer having an air guide at collector entry.

\subsection{Initial Moisture Content and Drying Experiments.}

The initial moisture content of mango was found to be $5.9 \mathrm{~kg}$ water $/ \mathrm{kg}$ dry matter ( $85.5 \%$ wet basis) and this value is comparable to initial moisture contents obtained by Touré and Kibangu-Nkembo [23] of 84\% (wet basis) and Ajila et al. [24] of $81 \%$ (wet basis).

The mango drying curve is shown in Figure 9 with the moisture content on dry basis plotted against drying time. The figure shows that the moisture content decreases with drying time, with a very sharp decrease in the first 4 hours and very low reduction thereafter. This curve is similar to what Akoy [25] obtained for solar mango drying in Sudan.

The final moisture content was found to be $0.15 \mathrm{~kg}$ water/ kg dry matter (13.0\% wet basis) and this was reached in 9.5 hours. After this, any further drying resulted in no further weight loss; hence this was considered as the equilibrium moisture content under the air conditions in the drying unit. The total drying time of 9.5 hours required more than a day of drying; hence 7 hours was used on the first day of drying because a typical experimental day was from 09:00 hours to 16:00 hours and 2.5 hours on the following day.

The final moisture contents of the dried mango in this study compare well with what has been reported previously by Dissa et al. [26] and Goyal et al. [27] of 13.79\% (wet basis) and $12 \%$ (wet basis), respectively.

Figures 10(a) and 10(b) show the drying rate of mango plotted against moisture content and drying time, respectively. The curves do not show any constant rate period but have at least one falling rate period. The drying rate is highest at the beginning when the moisture content is also at its maximum. This result is similar to what other studies found: Akoy [28] for convective drying of mango slices, Jokić et al. [29] for hot air tray drying of apples, and Toğrul and Pehlivan [30] for open-air sun drying of apricots, grapes, peaches, figs, and plums. Guiné [31] explained that there are generally two stages in the falling rate period with the first one being characterised by moisture evaporation from the surface being higher than the rate of moisture movement to the surface. Then during the second stage heat and mass transfer takes longer due to reduced moisture content as the moisture content reaches the equilibrium moisture content.

The conditions of air under which the mango was dried in the dryer are shown in Figures 11 and 12 for air temperature and relative humidity, respectively.

With the solar radiation varying between a minimum of $568.4 \mathrm{~W} / \mathrm{m}^{2}$ and a maximum of $999.5 \mathrm{~W} / \mathrm{m}^{2}$ as shown in Figure 11, the resulting pattern of dryer air temperatures shows that $T_{\mathrm{c}}$ was greater than $T_{\mathrm{d}}, T_{\mathrm{ch}}$, and $T_{\mathrm{am}}$. A maximum air temperature of $65.8^{\circ} \mathrm{C}$ was recorded at the collector unit while the product was loaded in the drying unit. This is in contrast with the no-load experiment discussed in Section 3.2 where the maximum air temperature occurred in the drying unit. With the product loaded in the drying unit, the air from the collector loses its heat to the product to evaporate moisture and thus results in a drop in the air temperature as it passes over the product from $T_{\mathrm{c}}$ to $T_{\mathrm{d}}$.

Despite the temperature drop which was expected due to the heat and mass transfer processes, the air temperatures in the drying unit remained well above ambient by over $10^{\circ} \mathrm{C}$ for most of the day. A further drop from $T_{\mathrm{d}}$ to $T_{\mathrm{ch}}$ by an average value of $4.5^{\circ} \mathrm{C}$ at the chimney unit was registered although $T_{\mathrm{ch}}$ remained above $T_{\mathrm{am}}$ by $12.1^{\circ} \mathrm{C}$. The ability of the chimney to keep the air temperature above ambient was desirable for the generation of buoyancy pressure head.

The relative humidities associated with the air temperatures in Figure 11 are shown in Figure 12.

The ambient relative humidity varied between $28.2 \%$ and $38.9 \%$ as shown in Figure 12. As observed in the case of air temperatures, the relative humidity also exhibited a dependence on the solar radiation. $\mathrm{RH}_{\mathrm{am}}, \mathrm{RH}_{\mathrm{d}}$, and $\mathrm{RH}_{\mathrm{c}}$ started reducing at 09:00 hours and continued reducing until 14:00 hours when a small increase was observed due to the decrease in the solar radiation. Therefore the relative humidity followed a diurnal regime defined by the solar radiation as reported by Pangavhane et al. [32]. At the drying unit where the air picks up moisture from the product, $\mathrm{RH}_{\mathrm{d}}$ rose above $\mathrm{RH}_{c}$ but was below $\mathrm{RH}_{\mathrm{am}}$. The average relative humidity values were $30.8 \%, 6.4 \%$, and $8.4 \%$ for $\mathrm{RH}_{\mathrm{am}}, \mathrm{RH}_{\mathrm{c}}$, and $\mathrm{RH}_{\mathrm{d}}$, respectively. It can be seen from these values that the relative humidity of the air leaving the drying unit (8.4\%) was still relatively low compared to ambient (30.8\%) and could still be used sufficiently for drying.

3.4. Evaluation of the Dryer Performance. The collector, drying, and pick-up efficiencies were found to be $24.7 \%, 12.8 \%$, and $35.0 \%$, respectively. These efficiencies are similar to those obtained by Schiavone [33] for the collector, drying, and pick-up efficiencies of $29.05 \%, 10.8 \%$, and $33.9 \%$, respectively, for a natural convection solar dryer. Further, Brenndorfer et al. [15] estimated the typical drying efficiency of natural convection dryers to be in the range of 10 and $15 \%$, and therefore the drying efficiency of $12.8 \%$ found in this study is within the two limits. From these results, it can be inferred that natural convection systems are generally characterised by low efficiencies. 


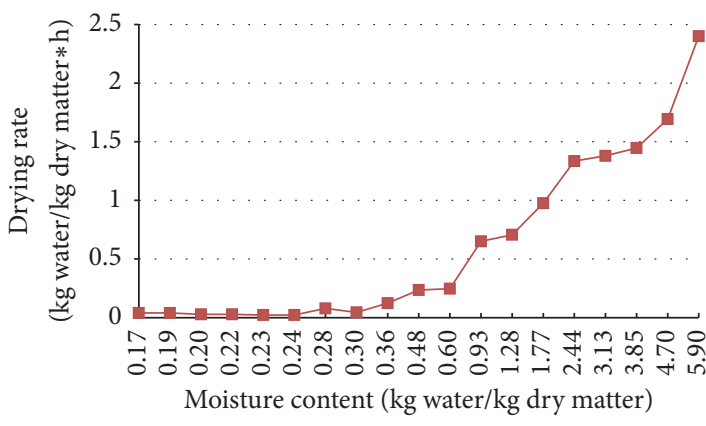

(a) Drying rate against moisture content

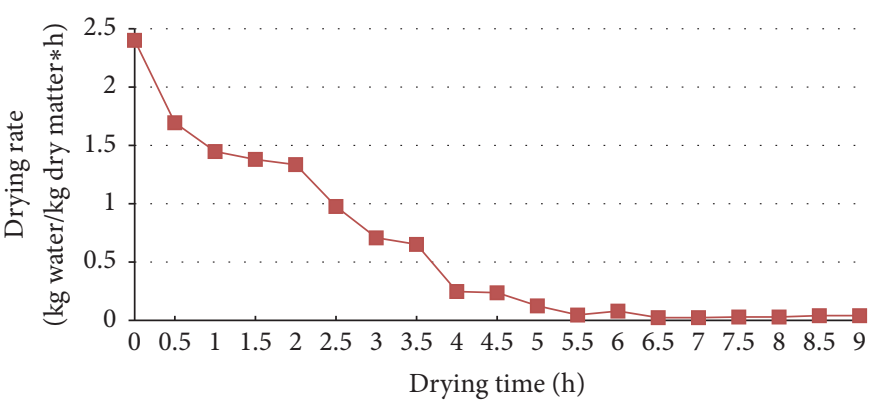

(b) Drying rate against drying time

Figure 10

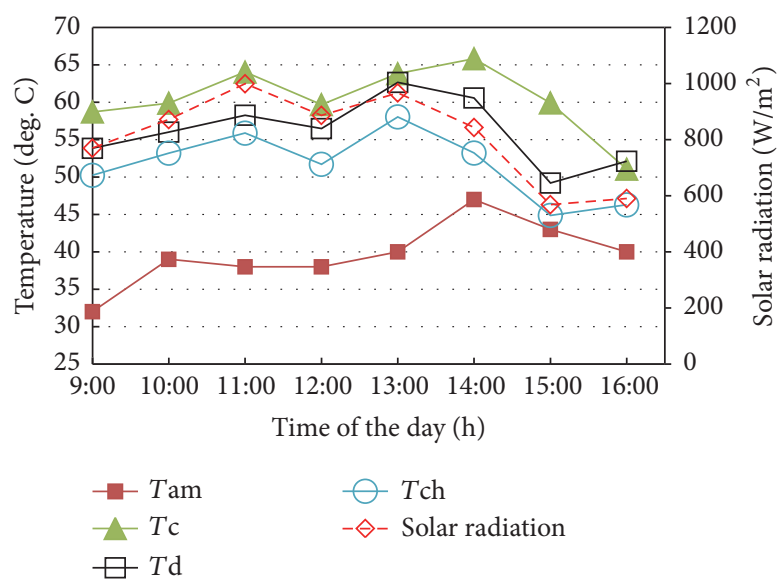

FIGURE 11: Air temperatures during mango drying experiments.

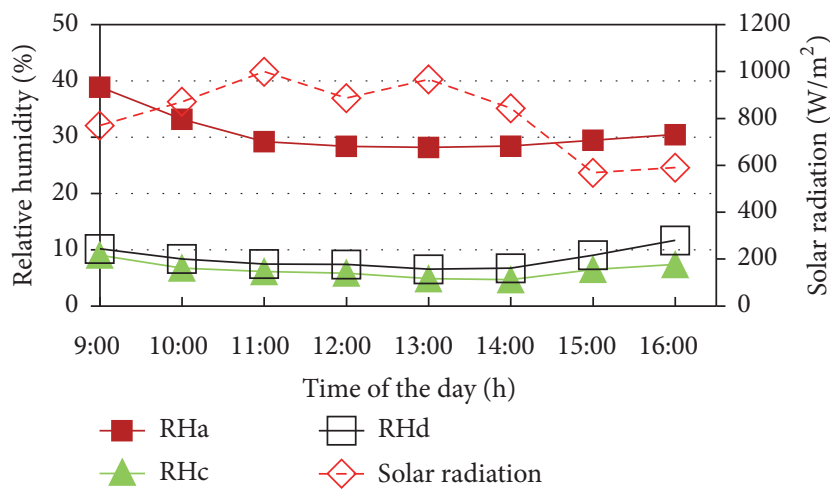

FIGURE 12: Relative humidity during mango drying experiments.

\section{Conclusions}

A horizontal configuration of air entry into the collector results in a bidirectional air flow in the dryer which is influenced by external wind flow. Incorporation of an air guide at the collector in order to block air entering directly in a horizontal direction, but in a vertical direction, resulted in a unidirectional air flow in the dryer, which is desirable.

It took 9.5 hours to dry mango slices from a moisture content of $85.5 \%$ wet basis to a final safe moisture content of
13.0\% wet basis which compares well with what others have reported.

Besides the drying time as one of the performance evaluation parameters for the dryer, the collector, drying, and pick-up efficiencies were calculated and found to be $24.7 \%$, $12.8 \%$, and $35.0 \%$, respectively, which were typical of natural convection dryers according to the reviewed literature.

Although the chimney air temperature above ambient was low at $12.1^{\circ} \mathrm{C}$, its performance was sufficient in driving the flow of air through the dryer.

\section{Conflicts of Interest}

The authors hereby declare that there are no conflicts of interest regarding the publication of this paper.

\section{Acknowledgments}

The authors are highly grateful to the European Commission (EACEA) through the Mobility to Enhance Training of Engineering Graduates in Africa (METEGA) project for awarding Sam Cherotich the scholarship to pursue a MEngAgricultural Engineering at the University of Zambia.

\section{References}

[1] A. Phiri, "Post-harvest Losses of Fruits and Vegetables in Zambia," in AARDO Workshop on Technology on Reducing Post-harvest Losses and Maintaining Quality of Fruits and Vegetables, pp. 197-204, 2010, http://ir.tari.gov.tw:8080/bitstream/ 345210000/2830/1/publication_no147_21.pdf.

[2] M. Kumar, S. K. Sansaniwal, and P. Khatak, "Progress in solar dryers for drying various commodities," Renewable \& Sustainable Energy Reviews, vol. 55, pp. 346-360, 2016.

[3] A. Fudholi, K. Sopian, M. H. Ruslan, M. A. Alghoul, and M. Y. Sulaiman, "Review of solar dryers for agricultural and marine products," Renewable \& Sustainable Energy Reviews, vol. 14, no. 1, pp. 1-30, 2010.

[4] I. N. Simate, "Optimization of mixed-mode and indirect-mode natural convection solar dryers," Journal of Renewable Energy, vol. 28, no. 3, pp. 435-453, 2003.

[5] A. Sharma, C. R. Chen, and N. Vu Lan, "Solar-energy drying systems: a review," Renewable \& Sustainable Energy Reviews, vol. 13, no. 6-7, pp. 1185-1210, 2009. 
[6] P. Schirmer, S. Janjai, A. Esper, R. Smitabhindu, and W. Mühlbauer, "Experimental investigation of the performance of the solar tunnel dryer for drying bananas," Journal of Renewable Energy, vol. 7, no. 2, pp. 119-129, 1996.

[7] B. K. Bala, M. R. A. Mondol, B. K. Biswas, B. L. Das Chowdury, and S. Janjai, "Solar drying of pineapple using solar tunnel drier," Journal of Renewable Energy, vol. 28, no. 2, pp. 183-190, 2003.

[8] M. A. Hossain and B. K. Bala, "Drying of hot chilli using solar tunnel drier," Solar Energy, vol. 81, no. 1, pp. 85-92, 2007.

[9] M. A. Leon, S. Kumar, and S. C. Bhattacharya, "A comprehensive procedure for performance evaluation of solar food dryers," Renewable \& Sustainable Energy Reviews, vol. 6, no. 4, pp. 367393, 2002.

[10] S. Cherotich, Experimental investigation and mathematical modelling of a natural convection solar tunnel fruit dryer [Master Thesis], Master of Engineering dissertation, University of Zambia, Lusaka, Zambia, 2016.

[11] S. Cherotich and I. N. Simate, "Experimental investigation and mathematical modelling of a natural convection solar tunnel dryer," International Journal of Scientific \& Engineering Research, vol. 7, no. 5, pp. 597-603, 2016.

[12] J. E. Berinyuy, J. K. Tangka, and G. M. Weka Fotso, "Enhancing natural convection solar drying of high moisture vegetables with heat storage," Agricultural Engineering International: CIGR Journal, vol. 14, no. 1, pp. 141-148, 2012.

[13] A. Esper and W. Mühlbauer, "Solar tunnel dryer for fruits," Plant Research and Development, vol. 44, no. 4, pp. 61-64, 1996.

[14] E. Akoy, M. A. Ismail, E. F. A. Ahmed, and W. Luecke, "Design and construction of a solar dryer for mango slices," in Proceedings of the International Research on Food Security, Natural Resource Management and Rural Development-Tropentag, p. 94, University of Bonn, Bonn, Germany, 2006.

[15] B. Brenndorfer, L. Kennedy, and G. Mrema, Solar Dryers: Their Role in Post-Harvest Processing, Commonwealth Secretariat, 1987.

[16] O. V. Ekechukwu and B. Norton, "Review of solar-energy drying systems III: low temperature air-heating solar collectors for crop drying applications," Energy Conversion and Management, vol. 40, no. 6, pp. 657-667, 1999.

[17] E. K. Akpinar, "Determination of suitable thin layer drying curve model for some vegetables and fruits," Journal of Food Engineering, vol. 73, no. 1, pp. 75-84, 2006.

[18] AOAC, Official Methods of Analysis, Association of Official Analytical Chemists International, Washington DC, WA, USA, 2005.

[19] H. P. Garg and J. Prakash, Solar Energy, Fundamentals and Applications, Tata McGraw-Hill Publishing Company Limited, New Delhi, India, 1st edition, 2007.

[20] G. A. Mastekbayeva, M. A. Leon, and S. Kumar, "Performance evaluation of a solar tunnel dryer for chilli drying," in Asean Seminar and Workshop on Solar Drying Technology, 1998, http://www.faculty.ait.asia/kumar/rets/Publications/PERFORMANCE-SOLAR\%20DRYER-pitsanulok.pdf\&gt.

[21] R. J. Moffat, "Describing the uncertainties in experimental results," Experimental Thermal and Fluid Science, vol. 1, no. 1, pp. 3-17, 1988.

[22] National Aeronautics and Space Administration, Measurement Uncertainty Analysis Principles and Methods-NASA Measurement Quality Assurance Handbook-ANNEX 3, NASA-HDBK8739.19-3, National Aeronautics and Space Administration, Washington D.C., WA, USA, 2010.
[23] S. Touré and S. Kibangu-Nkembo, "Comparative study of natural solar drying of cassava, banana and mango," Journal of Renewable Energy, vol. 29, no. 6, pp. 975-990, 2004.

[24] C. M. Ajila, S. G. Bhat, and U. J. S. P. Rao, "Valuable components of raw and ripe peels from two Indian mango varieties," Food Chemistry, vol. 102, no. 4, pp. 1006-1011, 2007.

[25] E. O. M. Akoy, Mathematical modelling of solar drying of mango slices [Ph.D. Thesis], University of Khartoum, Sudan, 2007.

[26] A. O. Dissa, J. Bathiebo, S. Kam, P. W. Savadogo, H. Desmorieux, and J. Koulidiati, "Modelling and experimental validation of thin layer indirect solar drying of mango slices," Journal of Renewable Energy, vol. 34, no. 4, pp. 1000-1008, 2009.

[27] R. K. Goyal, A. R. P. Kingsly, M. R. Manikantan, and S. M. Ilyas, "Thin-layer drying kinetics of raw mango slices," Biosystems Engineering, vol. 95, no. 1, pp. 43-49, 2006.

[28] E. O. M. Akoy, "Experimental characterization and modeling of thin-layer drying of mango slices," International Food Research Journal, vol. 21, no. 5, pp. 1911-1917, 2014.

[29] S. Jokić, D. Velić, M. Bilić, J. Lukinac, M. Planinić, and A. N. A. Bucić-Kojić, "Influence of process parameters and pretreatments on quality and drying kinetics of apple samples," Czech Journal of Food Sciences, vol. 27, no. 2, pp. 88-94, 2009.

[30] I. T. Toğrul and D. Pehlivan, "Modelling of thin layer drying kinetics of some fruits under open-air sun drying process," Journal of Food Engineering, vol. 65, no. 3, pp. 413-425, 2004.

[31] R. P. F. Guiné, "Drying pears," in Handbook of Food Science, Technology and Engineering, Y. H. Hui, Ed., vol. 3, pp. 105/1105/13, CRC Taylor \& Francis, Boca Raton, FL, USA, 2006.

[32] D. R. Pangavhane, R. L. Sawhney, and P. N. Sarsavadia, "Design, development and performance testing of a new natural convection solar dryer," Energy, vol. 27, no. 6, pp. 579-590, 2002.

[33] F. Schiavone, Development and Evaluation of a Natural Convection Solar Dryer For Mango in Rural Haitian Communities [Master Thesis], Univeristy of Florida, 2011. 


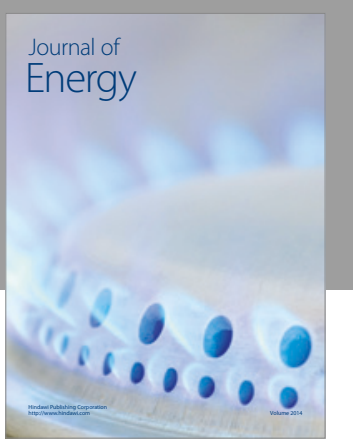

Journal of

Industrial Engineering
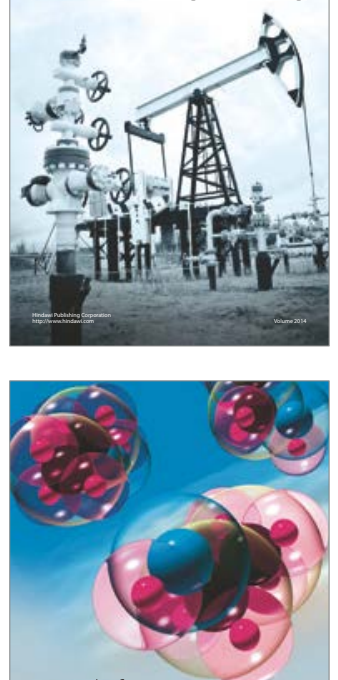

Fuels
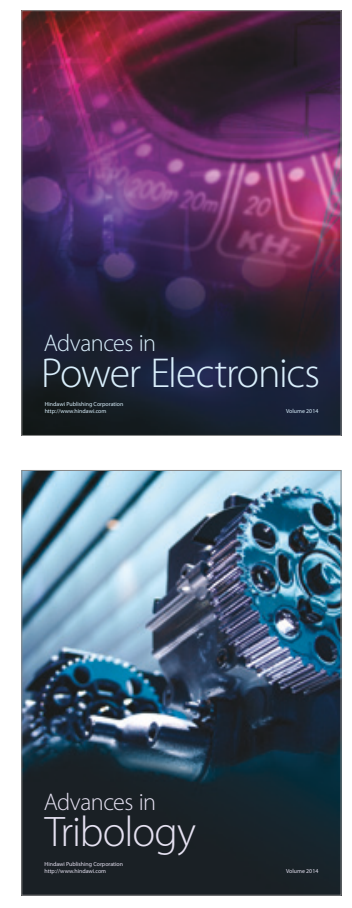
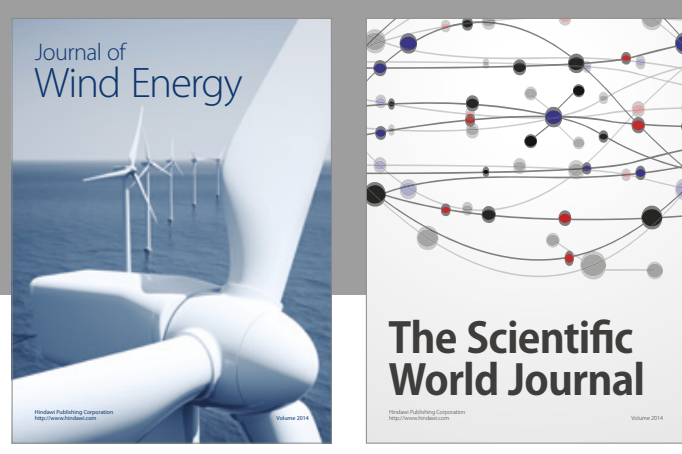

The Scientific World Journal
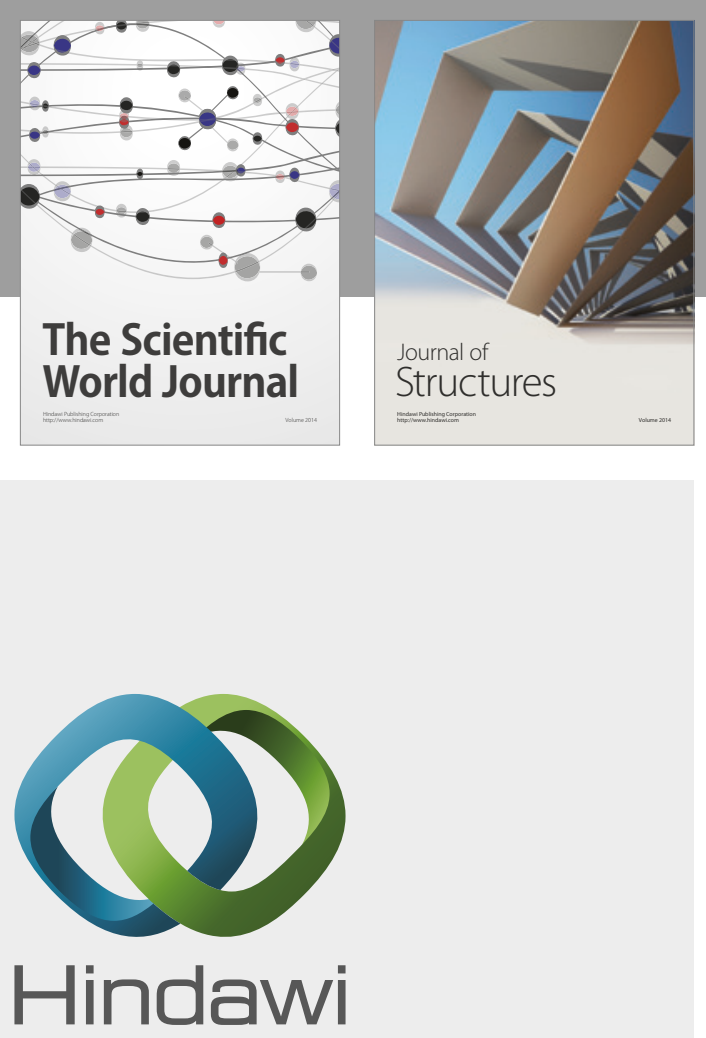

Submit your manuscripts at

https://www.hindawi.com
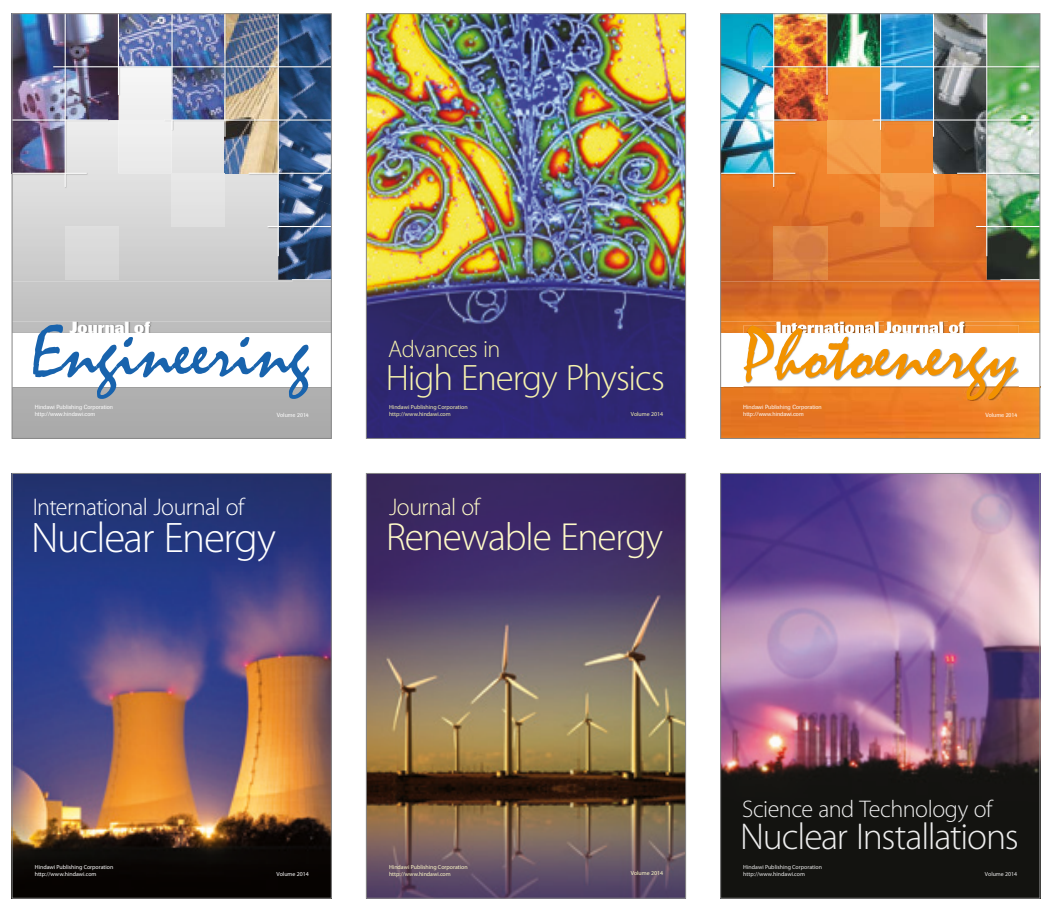

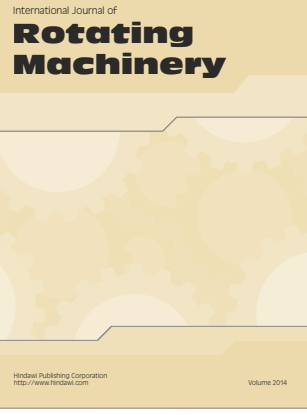

Journal of

Petroleum Engineering

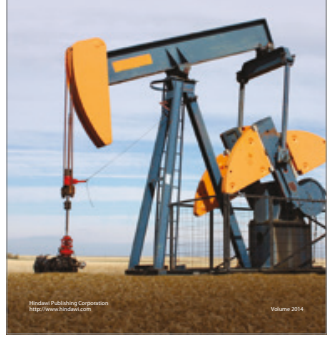

Journal of
Solar Energy
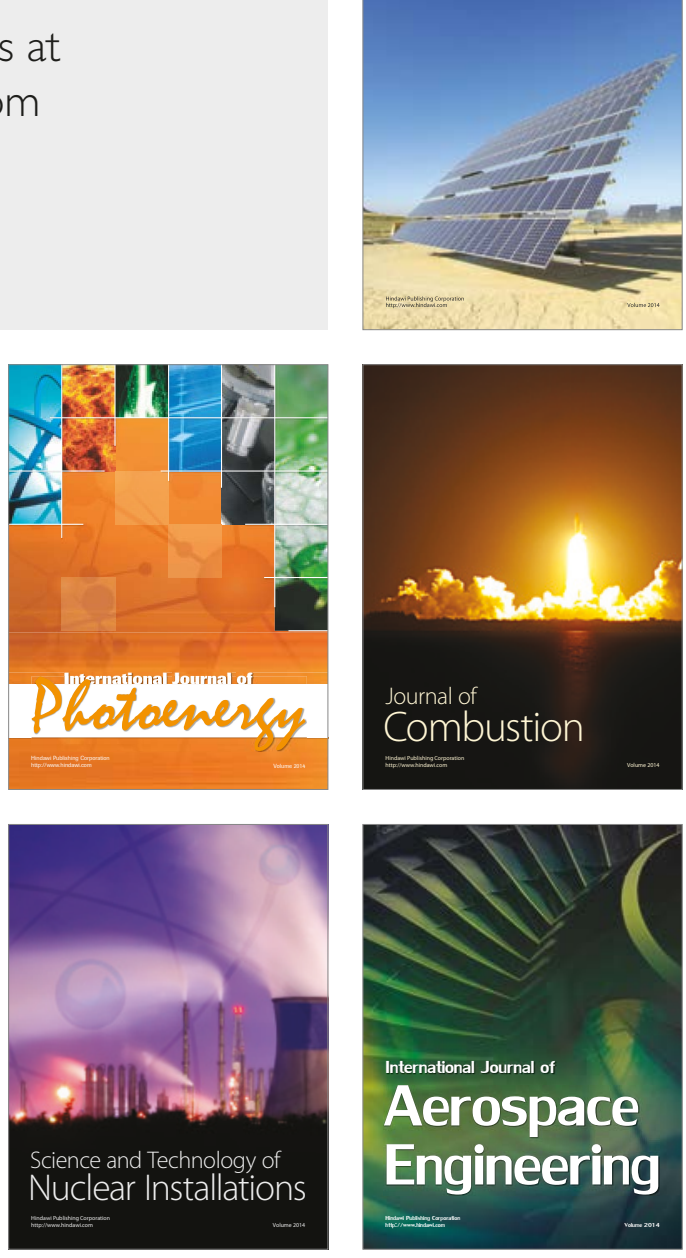